University of Wollongong

Research Online

Faculty of Social Sciences - Papers (Archive) Faculty of Arts, Social Sciences \& Humanities

2016

The (possibly negative) effects of physical activity on executive functions: Implications of the changing metabolic costs of brain development

Steven J. Howard

University of Wollongong, stevenh@uow.edu.au

Caylee J. Cook

University of Cape Town

Rihlat Said-Mohamed

University of Witwatersrand

Shane A. Norris

University of Witwatersrand

Catherine E. Draper

University of Cape Town

Follow this and additional works at: https://ro.uow.edu.au/sspapers

Part of the Education Commons, and the Social and Behavioral Sciences Commons

Research Online is the open access institutional repository for the University of Wollongong. For further information contact the UOW Library: research-pubs@uow.edu.au 


\title{
The (possibly negative) effects of physical activity on executive functions: Implications of the changing metabolic costs of brain development
}

\author{
Abstract \\ Background: An area of growth in physical activity research has involved investigating effects of physical \\ activity on children's executive functions. Many of these efforts seek to increase the energy expenditure \\ of young children as a healthy and low-cost way to affect physical, health, and cognitive outcomes. \\ Methods: We review theory and research from neuroscience and evolutionary biology, which suggest that \\ interventions seeking to increase the energy expenditure of young children must also consider the \\ energetic trade-offs that occur to accommodate changing metabolic costs of brain development. Results: \\ According to Life History Theory, and supported by recent evidence, the high relative energy-cost of early \\ brain development requires that other energy-demanding functions of development (ie, physical growth, \\ activity) be curtailed. This is important for interventions seeking to dramatically increase the energy \\ expenditure of young children who have little excess energy available, with potentially negative cognitive \\ consequences. Less energy-demanding physical activities, in contrast, may yield psychosocial and \\ cognitive benefits while not overburdening an underweight child's already scarce energy supply. \\ Conclusions: While further research is required to establish the extent to which increases in energy- \\ demanding physical activities may compromise or displace energy available for brain development, we \\ argue that action cannot await these findings.
}

\section{Keywords}

physical, development, effects, (possibly, executive, functions:, implications, changing, metabolic, costs, brain, negative), activity

\section{Disciplines}

Education | Social and Behavioral Sciences

\section{Publication Details}

Howard, S. J., Cook, C. J., Said-Mohamed, R., Norris, S. A. \& Draper, C. E. (2016). The (possibly negative) effects of physical activity on executive functions: Implications of the changing metabolic costs of brain development. Journal of Physical Activity and Health, 13 (9), 1017-1022. 
6 The (Possibly Negative) Effects of Physical Activity on Executive Functions: Implications of 7 the Changing Metabolic Costs of Brain Development

8

9

10 Manuscript Type: Review

11

12 Keywords: nutrition; neuroscience; psychology; risks of exercise; youth

13

14 Abstract Word Count: 200 words

15

16 Manuscript Word Count (Text + References): 4,667 words

17

18 Date of Revised Manuscript Submission: 1 March 2016

19

20

21

22

23 


\section{Abstract}

25 Background: An area of growth in physical activity research has involved investigating 26 effects of physical activity on children's executive functions. Many of these efforts seek to 27 increase the energy expenditure of young children as a healthy and low-cost way to affect 28 physical, health, and cognitive outcomes. Methods: We review theory and research from 29 neuroscience and evolutionary biology, which suggest that interventions seeking to increase the energy expenditure of young children must also consider the energetic trade-offs that

31 occur to accommodate changing metabolic costs of brain development. Results: According to 32 Life History Theory, and supported by recent evidence, the high relative energy-cost of early 33 brain development requires that other energy-demanding functions of development (i.e., 34 physical growth, activity) be curtailed. This is important for interventions seeking to dramatically increase the energy expenditure of young children who have little excess energy available, with potentially negative cognitive consequences. Less energy-demanding physical activities, in contrast, may yield psychosocial and cognitive benefits while not overburdening an underweight child's already scarce energy supply. Conclusions: While further research is required to establish the extent to which increases in energy-demanding physical activities may compromise or displace energy available for brain development, we argue that action cannot await these findings. 
44 The (Possibly Negative) Effects of Physical Activity on Executive Functions: Implications of

\section{the Changing Metabolic Costs of Brain Development}

An area of recent growth in physical activity research has involved investigating the effects of physical activity not just on physical (e.g., motor development) and health outcomes (e.g., body composition), but also cognitive outcomes in children. Particular interest has been directed toward executive functions (EFs), given mounting evidence for their relation to: (i) school readiness, academic learning, and success (e.g., literacy, numeracy, learning more broadly) ${ }^{1,2}$; (ii) social and emotional outcomes (e.g., theory of mind, moral conduct) ${ }^{3}$; and (iii) developmental disorders (e.g., ADHD) ${ }^{4}$. EFs refer to cognitive control processes that allow individuals to activate, maintain, and manipulate information in mind (working memory), resist task-irrelevant impulses and distractions (inhibition), and flexibly shift attention between tasks, rules, or requirements (shifting). EFs thus represent an interesting target for intervention in childhood, given that early EF development appears to set the stage for a broad range of later outcomes.

Whereas recent attempts to support and enhance EFs by development researchers have often involved computerized 'brain training' programs (which now constitutes a more than $\$ 1$ billion industry $)^{5}$, physical activity researchers have sought to evaluate whether, and under what conditions, engaging in physical activity might support the development of EFs. It is postulated that physical activities serve to engage and extend higher-order cognition through their physiological, morphological, and neurochemical effects on the brain. ${ }^{6}$ Research in this area has increasingly focused on the early years of life, as intervening in these formative years may generate a more stable and lasting change. ${ }^{7}$ If a cause and effect relationship exists, according to this line of reasoning, physical activity may thus represent a healthy and low-cost way to - at least indirectly - affect a range of outcomes that extend beyond those 
68 already well established in the physical activity literature (e.g., cardiovascular health and academic achievement). ${ }^{8-10}$

Research in this area, however, has found at best mixed results. Some studies have shown a modest improvement in EFs after either acute aerobic exercise ${ }^{11}$ or chronic aerobic exercise. ${ }^{12}$ Yet two separate meta-analyses have indicated little to no effect of aerobic activity on subsequent executive functioning. ${ }^{13,14}$ There has been a similar lack of consistent success with resistance training interventions. ${ }^{15}$ Despite these findings, promising results have been shown with martial arts, ${ }^{16}$ yoga,${ }^{17}$ and some other sports, ${ }^{18}$ which have yielded moderate effects on EFs and/or EF-related abilities. On this basis, it has been suggested that what is done during physical activity (i.e., physical activity that provides opportunity to engage and challenge EFs) may be the most important factor contributing to group-level effects of physical activity on EFs. ${ }^{6,19}$ In fact, Best states in his critical review, "cognitively-engaging exercise appears to have a stronger effect than non-engaging exercise on children's executive function" (p. 331). ${ }^{6}$ He further asserts that efforts to understand the link between physical activity and cognition are worthwhile, given the importance of physical activity for the developing mind.

What may be overlooked in this emerging line of research, however, are the individual or sub-group level effects of physical activity on EFs and cognitive development more broadly. On the one hand, there are known health benefits of physical activity (e.g., obesity prevention, gross motor competence, positive psychosocial and health outcomes). ${ }^{20-23}$ Also well established are the negative consequences of unhealthy weight status ${ }^{24,25}$ and sedentary behaviour in childhood (e.g., overweight, unfavourable psychosocial health and cognitive outcomes). ${ }^{26-29}$ Yet insights from neuroscience (PET and MRI data) ${ }^{30}$ and evolutionary biology (Life History Theory applied to humans) ${ }^{31}$ suggest the need to consider the impact of 
the metabolic costs of physical activity in terms of energy expenditure across different stages of life and individuals' metabolic conditions.

\section{The Changing Metabolic Costs of Brain Development}

Life History Theory (LHT), which is derived from evolutionary biology and ecology, ${ }^{31}$ seeks to explain the processes, timing, and evolutionary forces that shape the timing and form of life events (e.g., early development, maturation, fertility, mortality). ${ }^{32}$ More specifically, LHT proposes that survival requires the 'capture' of resources (e.g., energy) from the environment and subsequent 'allocation' of resources (e.g., energy, time) to activities that are essential to maximize fitness (i.e., reproduction and survival). Given that resources available to an individual are finite (often termed an 'energy budget' in the case of energy resources), ${ }^{32}$ allocation of energy thus must involve trade-offs with other energy-expending pursuits. This notion of functional trade-offs to accommodate our finite energy budget is supported by evidence that energy expenditure scales closely to body mass, ${ }^{33}$ which suggests a ceiling on the typical energy expenditure for a given body size. While evidence shows humans to have a low energy budget relative to their body mass index, compared to other placental animals, it is notable that this overall energy budget appears to be largely unaffected by physical activity levels or energy input ${ }^{34}$ (and instead may relate to increased investment in brain structures).

LHT further posits that the allocation of energy and time changes with life history stages (in infancy more energy is allocated to physical and brain growth, whereas in adolescence the energy is more often allocated to reproduction) and circumstances (i.e., ecological factors, health, and social context). ${ }^{35,36}$ In humans, LHT suggests that resources can be allocated to three fundamental functions: maintenance, growth, and reproduction. ${ }^{36}$ According to the principle of allocation, trade-offs are expected between these functions such that greater resource allocation to one function depletes the resources available for another function. 
116 Particularly relevant to infant, child, and adolescent development are the energetic trade-

117 offs that must occur to ensure physical growth, brain development, the learning of complex

118 cultural practices, and mastery of energy acquisition skills. While it is clear that the pre-adult

119 life-stage is unusually long by primate standards, ${ }^{37}$ such that a sizeable proportion of pre-

120 adult growth does not occur until adolescence, ${ }^{38}$ less clear are the evolutionary reasons for

121 such a protracted developmental phase. ${ }^{30}$ From a life history theory perspective, it has been

122 suggested that the high relative energy-cost of brain development requires that other energy-

123 demanding functions of development be curtailed. $32,39,40$

124 In line with this assertion, research by Kuzawa et al. suggests that, in early childhood, a

125 down-regulation in energy devoted to physical growth (e.g., body weight) coincides with an

126 increase in the energy demands for brain development. ${ }^{30}$ Specifically, using pooled PET and

127 MRI data the researchers found an average pattern that, beginning at around 6 months of age,

128 steady increases in brain glucose demands were accompanied by proportional decreases in

129 body-weight growth. In contrast to previous suggestions of peak brain energy costs at birth, ${ }^{41}$

130 Kuzawa and colleagues found that the glucose demands of the brain peaked at around 4.3

131 years of age - accounting for approximately $65 \%$ of resting metabolic rates and $43 \%$ of daily

132 energy requirements - which co-occurred with a low point in body-growth energy demands.

133 After this age, gradual physical growth (i.e., height, weight) was accompanied by decreases

134 in brain energy demands, as both converged toward adult levels. ${ }^{30}$

135 In light of these findings, Kuzawa et al. propose that, in humans, physical growth and

136 activity may be attenuated in the early years to increase the energy available for brain

137 development. ${ }^{30}$ For typically developing children, Kuzawa et al.’s assertion receives support

138 from studies on primates and other non-human animals showing investment in locomotor

139 play carried "sizeable costs" to physical growth ${ }^{42,43}$, as well as longitudinal human research

140 suggesting physical activity levels may decrease across the preschool years ${ }^{44}$ as children 
141 approach the peak in brain glucose demands. Reasons for this physical activity decline are

142 likely complex and multi-factorial, however, as illustrated by evidence of a continued

143 decline in physical activity after brain energy demands begin to decrease. ${ }^{45}$ Nevertheless,

144 this decrease in physical activity levels coinciding with increasing brain glucose demands

145 suggests a potential compensatory relationship. If true, attenuation of physical-activity-based

146 energy expenditure in the early years may be especially pronounced in children who are

147 already energy-deficient.

148 Evidence suggesting a more pronounced decline in physical activity levels amongst

149 malnourished children is mixed, however, and is exacerbated by the different aspects of

150 malnourishment that have been used to characterize children in these studies (e.g.

151 underweight, stunting, wasting). Furthermore, some studies have compared undernourished

152 and adequately nourished children in terms of physical activity abilities, such as gross motor

153 skills and fitness, and have often found more similarities than differences. For instance, a

154 study in India with children (5-10 years old) with chronic protein energy malnutrition found

155 that malnourished and adequately nourished children were comparable in their motor speed

156 and coordination. ${ }^{46}$ Similarly, a South African study showed similarities in fitness between

157 undernourished and adequately nourished children (7-14 years), with undernourished

158 children actually performing better on some of the parameters, including a $1600 \mathrm{~m}$ run. ${ }^{47}$

159 In contrast, studies that have found associations between malnutrition and free-living

160 physical activity levels have more commonly found that underweight children are less likely

161 to engage in physical activity ${ }^{48}$ and that stunted children have lower levels of physical

162 activity and activity-based energy expenditure. ${ }^{49,50}$ Although studies have not always found

163 this decrement in physical activity levels in undernourished and stunted children, ${ }^{51-53}$ these

164 contradictory findings could be a product of differing home contexts (e.g., differences in free

165 living or habitual physical activity, such as household chores or activities). While this issue 
is currently speculative and undoubtedly requires further study, such as whether, how and under what conditions the patterns identified by Kuzawa et al. ${ }^{30}$ might result in individuallevel trends, it can be argued that action cannot await these findings. That is, if at least some of this decrement in early childhood physical activity is due to the brain's increased energy requirements, this suggests that interventions seeking to dramatically increase the energy expenditure of young children who have little excess energy available (e.g., underweight or undernourished children) could have negative, rather than positive, cognitive consequences.

\section{Physical Activity and Malnutrition}

Undernutrition includes underweight (weight-for-age $<-2 \mathrm{SD}$ ), stunting (height-for-age $<$ -2SD), wasting (weight-for-height $<-2 \mathrm{SD}$ ), and thinness (BMI-for-age $<-2 \mathrm{SD}) .{ }^{54}$ Global prevalence of underweight and stunting in young children has decreased since 1990 (from $25 \%$ and $40 \%$ to $16 \%$ and $26 \%$, respectively, in 2011). ${ }^{55}$ Yet these statistics highlight that undernourished children should also be considered when planning early physical activity interventions, particularly in developing nations (where $17.4 \%$ of young children are estimated as underweight), and to a lesser extent in developed nations (in which $2.4 \%$ of young children are estimated to be underweight). ${ }^{55}$ That is, if the functional energetic tradeoff hypothesis is accurate, there may be potential cognitive repercussions of interventions that aim to significantly increase energy expenditure in children with already low 'energy budgets' (underweight, undernourished), which may divert energy away from brain development functions. This would be particularly problematic given that many of these energy-deficient children are found in disadvantaged circumstances, with already impaired cognitive development (including EFs) as a result of chronic nutrition deficits in early life. ${ }^{46,56,57}$

This hypothesis does not suggest that physical activity should be curtailed in the early years or that efforts to increase physical activity in this age group are not worthwhile. Rather, 
191 the logical extension of these ideas would suggest that these efforts should carefully consider

192 the unique (and possibly different) needs of the children being targeted. To illustrate, low-

193 and middle-income countries including South Africa, ${ }^{58}$ India, ${ }^{59}$ and Brazil ${ }^{60}$ face a double

194 burden of over- and under-nutrition. These burdens can occur within the same community, as

195 both under- and over-nutrition are associated with social and economic inequalities. ${ }^{58,61}$ In

196 settings such as these, it is therefore essential to promote physical activity as a means of

197 preventing and/or managing overweight and obesity in early childhood and later life. At the

198 same time, it is also important to understand the potential physiological consequences of

199 promoting dramatic energy expenditure increases with early childhood populations in which

200 under-nutrition is more prevalent.

201 Thus far most early childhood physical activity interventions have not differentiated their

202 approach based on weight status. Instead, studies have tended to introduce a general increase

203 in children's energy expenditure and examine its associated group-level physical benefits. ${ }^{62-68}$

204 Further, in such studies participants' weight status (underweight, normal weight, overweight,

205 obese) is rarely reported, thus making it difficult to estimate the impacts of the intervention

206 on underweight and undernourished children. Instead, participants' body composition is more

207 commonly measured as just one component of an outcome measure such as body mass index

208 (BMI), ${ }^{64,69,70}$ weight-for-height $\mathrm{z}$-score, ${ }^{64}$ or is used as a variable to evaluate initial group

209 equivalence. ${ }^{62,63,71}$ The one identified study reporting weight status of the preschool children

210 involved in a physical activity intervention included the expected proportion of children

211 classified as underweight (2.2\%). ${ }^{72}$ It therefore can be expected that other studies may have

212 also included children that have differing 'energy budgets' from their normal and overweight

213 peers, yet the intervention has uniformly sought to increase their energy expenditure through

214 physical activity. 
215 This appears to be an under-investigated issue, however, with no literature found on 216 physical activity interventions specifically targeting undernourished children and/or looking

217 at the cognitive effects of increasing physical activity for undernourished, young children.

218 That is, of the studies that do collect cognitive data from children (generally older) after a 219 physical activity intervention, ${ }^{11,73,74}$ few report BMI, and none that could be found looked at 220 the cognitive effects of physical activity for undernourished children. It is important to note that the evidence-based energetic trade-off hypothesis does not suggest that physical activity should be discouraged or curtailed in underweight children, or that attempts to promote

223 physical activity in these groups should be avoided. Rather, in such cases physical activity 224 may still play an important role in early development. Yet, according to this hypothesis, the 225 means of intervention must be carefully considered and the approach taken may necessarily require a departure from simply increasing the energy expenditure of these children through energy-demanding physical activity. Less energy-demanding physical activities-for example, those that emphasize gross motor development-may yield important psychosocial $^{75-77}$ and cognitive benefits ${ }^{78}$ while not overburdening an underweight child's already scarce supply of energy. Where possible, it may be beneficial for these initiatives to also be accompanied by nutrition interventions for children with low energy budgets, considering the negative effect of poor nutrition on cognitive development. ${ }^{46,57}$

\section{Conclusions and Future Directions}

The implications of the changing metabolic costs of brain development-specifically the

235 down-regulation of energy for physical growth and concomitant up-regulation of energy

236 allocated to brain development in the early years-is an important but under-investigated area.

237 For instance, further research is required to establish the extent to which increases in energy-

238 demanding physical activities may compromise or displace the energy available for human

239 brain development and the extent to which this manifests at the individual level. For instance, 
240 the relatively low energy expenditure of humans relative to body mass ${ }^{34}$ could be posited as a

241 potential mechanism that could at least partially buffer against this energetic trade-off issue.

242 This possibility appears unlikely, however, in light of available human and primate research.

243 Research with Assamese macaques is at least suggestive in this regard, showing that energy-

244 intensive physical activity may reduce the energy available for physical growth (contrary to

245 previous theorizing that only surplus energy would be used). ${ }^{42}$ Alternatively, rather than a

246 direct cause and effect relationship, there may be a set of common factors that negatively

247 impact early physical activity and cognitive development. These may include poor- or under-

248 nutrition, psychosocial stressors, or other factors associated with socioeconomic

249 deprivation. ${ }^{79,80}$ As such, future research should seek to further understand how changing

250 metabolic costs, brain development, and physical activity interact over the course of

251 development (and especially in the preschool years). This may involve research investigating

252 the association between body composition (e.g., lean and fat mass) and aspects of physical

253 activity (e.g., intensity, type, dose, patterns) in settings in transition where malnutrition is

254 more prevalent. While there has begun empirical research into these questions in

255 disadvantaged areas of South Africa, early presentation of the energetic trade-off hypothesis

256 serves as: (a) a theoretical basis from which to contextualize this empirical data; (b) a prompt

257 for physical activity researchers to consider these hypotheses in their research, in advance of

258 these initial empirical findings; and (c) a stimulus for international evaluations of this

259 hypothesis using existing and new datasets (to expedite replications that otherwise would

260 await publication of initial empirical data). Even in the absence of this empirical work, there

261 is a plausible hypothesis that suggests physical activity initiatives in the early years should

262 consider the varied energy budgets and nutrition needs of children to optimize both group-

263 and individual-level outcomes. 
Running Head: EFFECT OF PHYSICAL ACTIVITY ON EXECUTIVE FUNCTIONS

\section{Funding}

265 Support for this paper was provided by the DST/NRF Centre of Excellence in Human 266 Development. 


\section{References}

268 1. Blair C, Razza RP. Relating effortful control, executive function, and false belief

269 understanding to emerging math and literacy ability in kindergarten. Child Dev.

$270 \quad 2007 ; 78: 647-663$.

271 2. Bull R, Espy KA, Wiebe SA. Short-term memory, working memory, and executive

272 functioning in preschoolers: Longitudinal predictors of mathematical achievement at age 2737 years. Dev Neuropsychol. 2008;33:205-228.

274 3. Riggs NR, Jahromi LB, Razza RP, Dillworth-Bart JE, Müeller U. Executive function and 275 the promotion of social-emotional competence. J Appl Dev Psychol. 2006;27:300-309.

276 4. Casey BJ, Tottenham N, Fossella J. Clinical, imaging, lesion, and genetic approaches 277 toward a model of cognitive control. Dev Psychobiol. 2002;40:237-254.

278 5. Hayden EC. Treating schizophrenia: Game on. Nature. 2012;483:24-26.

279 6. Best JR. Effects of physical activity on children's executive function: Contributions of 280 experimental research on aerobic exercise. Dev Rev. 2010;30:331-351.

281 7. Wass SV, Scerif G, Johnson MH. Training attentional control and working memory - is 282 younger better? Dev Rev. 2012;32:360-387.

283 8. Donnelly JE, Lambourne K. Classroom-based physical activity, cognition, and academic 284 achievement. Prev Med. 2011;52:S36-S42.

9. Janssen I, Leblanc AG. Systematic review of the health benefits of physical activity and fitness in school-aged children and youth. Int J Behav Nutr Phy. 2010;7:1-16.

10. Strong WB, Malina RM, Blimkie CJR, et al. Evidence based physical activity for schoolage youth. J Paediatr. 2005;146:732-737.

11. Hillman CH, Pontifex MB, Raine LB, Castelli DM, Hall EE, Kramer AF. The effect of acute treadmill walking on cognitive control and academic achievement in preadolescent children. Neurosci. 2009;159:1044-1054. 
12. Davis CL, Tomporowski PD, Boyle CA, et al. Effects of aerobic exercise on overweight children's cognitive functioning: A randomized controlled trial. Res $Q$ Exercise Sport. 2007;78:510-519.

13. Angevaren M, Aufdemkampe G, Verhaar HJ, Aleman A, Vanhees L. Physical activity and enhanced fitness to improve cognitive function in older people without known cognitive impairment. Cochrane Db. 2008;3:CD005381.

14. Smith PJ, Blumenthal JA, Hoffman BM, et al. Psychosom Med. 2010;72: 239-252.

15. Liu-Ambrose T, Nagamatsu LS, Graf P, Beattie L, Ashe MC, Handy TC. Resistance training and executive functions: A 12-month randomized controlled trial. Arch Intern Med. 2010;170:170-178.

16. Lakes KD, Hoyt WT. Promoting self-regulation through school-based martial arts training. J Appl Dev Psychol. 2004;25:283-302.

17. Manjunath NK, Telles S. Improved performance in the Tower of London test following yoga. Indian J Physiol Pharm. 2001;45:351-354.

18. Davis CL, Tomporowski PD, McDowell JE, et al. Exercise improves executive function and achievement and alters brain activation in overweight children: A randomized,

19. Diamond A. Effects of physical exercise on executive functions: Going beyond simply moving to moving with thought. Ann Sport Med Res. 2015;2:1011-1015.

20. Martinez-Gomez D, Tucker J, Heelan KA, Welk GJ, Eisenmann JC. Associations between sedentary behavior and blood pressure in young children. Arch Pediatr Adolescent Med. 2009;163:724-730. for coronary heart disease risk factors in early childhood. Scand J Med Sci Spor. 2004;14:143-149. 
Running Head: EFFECT OF PHYSICAL ACTIVITY ON EXECUTIVE FUNCTIONS

22. te Velde SJ, van Nassau F, Uijtdewilligen L. Energy balance-related behaviours associated with overweight and obesity in preschool children: A systematic review of prospective studies. Obes Rev. 2012 ;13: 56-74.

23. Timmons BW, LeBlanc AG, Carson V, et al. Systematic review of physical activity and health in the early years (aged 0-4 years). Appl Physiol Nutr Me. 2012;37:773-792.

24. Ebbeling CB, Pawlak DB, Ludwig DS. Childhood obesity: Public-health crisis, common sense cure. Lancet. 2002;360: 473-482.

25. Lobstein T, Baur L, Uauy R. Obesity in children and young people: A crisis in public health. Obes Rev. 2004;5:4-85.

26. Byun W, Dowda M, Pate RR. Correlates of objectively measured sedentary behavior in US preschool children. Pediatrics. 2011;128:937-945.

27. Carson V, Kuzik N, Hunter S, et al. Systematic review of sedentary behavior and cognitive development in early childhood. Prev Med. 2015;78:115-122.

28. Kuhl ES, Clifford LM, Stark LJ. Obesity in preschoolers; Behavioral correlates and directions for treatment. Obesity. 2012;20:3-29.

29. LeBlanc AG, Spence JC, Carson V, et al. Systematic review of sedentary behaviour and health indicators in the early years (aged 0-4 years). Appl Physiol Nutr Me. 2012;37:753772.

30. Kuzawa CW, Chugani HT, Grossman LI, Lipovich L, Hof PR, Wildman DE. Metabolic costs and evolutionary implications of human brain development. PNAS. 2014;111:13010-13015.

31. Gadgil M, Bossert WH. Life historical consequences of natural selection. American Naturalist. 1970;104:1-24.

32. Kaplan HS, Gangestad SW. Life History Theory and evolutionary psychology. In: Buss DM, ed. Handbook of Evolutionary Psychology. New York: Wiley; 2005:68-95. 
Running Head: EFFECT OF PHYSICAL ACTIVITY ON EXECUTIVE FUNCTIONS

33. Keliber M. Body size and metabolism. Hilgardia. 1932;6:315-353.

34. Pontzer H, Raichlen DA, Gordon AD, et al. Primate energy expenditure and life history. PNAS. 2014:111;1433-1437.

35. Bogin B, Silva MIV, Rios L. Life history trade-offs in human growth: Adaptation or pathology? Am J Hum Biol. 2007;19:631-642.

36. Hochberg Z, Albertsson-Wikland K. Evo-devo of infantile and childhood growth. Pediatr Res. 2008;64:2-7.

37. Hill K. Life history theory and evolutionary anthropology. Evol Anthropol. 1993;2:7888.

38. Walker R, Hill K, Burger O, Hurtado AM. Life in the slow lane revisted: Ontogentic separation between Chimpanzees and humans. Am J Phys Anthropol. 2006;129:577-583.

39. Leonard WR, Robertson, ML. Nutritional requirements and human evolution: A bioenergetics model. Am J Hum Biol. 1992;4:179-195.

40. Navarette A, van Schaik CP, Isler K. Energetics and the evolution of human brain size. Nature. 2011;480:91-93.

41. Fonseca-Azevedo K, Herculano-Houzel S. Metabolic constraint imposes tradeoff between body and number of brain neurons in human evolution. PNAS. 2012;109:1857118576.

42. Berghänel A, Schülke O, Ostner J. Locomotor play drives motor skill acquisition at the expense of growth: A life history trade-off. Sci Advances. 2015;1:e1500451.

43. Théoret-Gosselin R, Hamel S, Côté S. The role of maternal behavior and offspring development in the survival of mountain goat kids. Oecologia. 2015:178;175-186.

44. Taylor RW, Williams SM, Farmer VL, Taylor BJ. Changes in physical activity over time in young children: A longitudinal study using accelerometers. PLOS One. 2013;8:e81567. 
45. Trost SG, Pate RR, Sallis JF, 2002. Age and gender differences in objectively measured physical activity in youth. Med Sci Sport Exer. 2013;34:350-355.

46. Kar BR, Rao SL, Chandramouli BA. Cognitive development in children with chronic protein energy malnutrition. Behav Brain Functions. 2008;4:31-42.

47. Monyeki MA, Kemper HCG, Koppes LLJ, Twisk JWR. Body composition and physical fitness of undernourished South African rural primary school children. J Clin Nutr. 2005;59:877-883.

48. Jones S, Hendricks S, Draper CE. Assessment of physical activity and sedentary behavior at preschools in Cape Town, South Africa. Child Obes. 2014;10:501-510.

49. Said-Mohamed R, Bernard JY, Ndzana A-C, Pasquet P. Is overweight in stunted preschool children in Cameroon related to reductions in fat oxidation, resting energy expenditure and physical activity? PLoS ONE. 2012;7:e39007-39009.

50. Wilson HJ, Dickinson F, Hoffman DJ, Griffiths PL, Bogin B, Varela-Silva MI. Fat free mass explains the relationship between stunting and energy expenditure in urban Mexican Maya children. Ann Hum Biol. 2012;39:432-439.

51. Casale D, Desmond C, Richter L. The association between stunting and psychosocial development among preschool children: A study using the South African Birth to Twenty cohort data. Child Care Hlth Dev. 2014;40:900-910.

52. Mamabolo RL, Kruger HS, Lennox A, et al. Habitual physical activity and body composition of black township adolescents residing in the North West Province, South Africa. Public Health Nutr. 2007;10:1047-1056.

53. Prista A, Maia JAR, Damasceno A, Beunen G. Anthropometric indicators of nutritional status: Implications for fitness, activity, and health in school-age children and adolescents from Maputo, Mozambique. Am J Clin Nutr. 2003;77:952-959.

54. World Health Organization. WHO child growth standards: length/height-for-age, 
Running Head: EFFECT OF PHYSICAL ACTIVITY ON EXECUTIVE FUNCTIONS

weight-for-age, weight-for-length, weight-for-height and body mass index-for-age: methods and development. Geneva: WHO; 2006.

55. United Nations Children's Fund, World Health Organization, The World Bank. UNICEF-WHO-World Bank joint child malnutrition estimates. Geneva: WHO; 2012.

56. Miranda MC, Nobrega FJ, Sato K, Pompeia S, Sinnes EG, Bueno OFA. Neuropsychology and malnutrition: A study with 7 to 10 years-old children in a poor community. Rev Bras Mat Infant. 2007;7:45-54.

57. Morgan KE. The cognitive effects of chronic malnutrition and environment on working memory and executive function in children. Independent Study Project ISP Collection. Paper 2053; 2015. Available from: http://digitalcollections.sit.edu/isp_collection/2053

58. Monyeki MA, Awotidebe A, Strydom GL, de Riddler JH, Mamabolo RL, Kemper HCG. The challenges of underweight and overweight in South African children: Are we winning or losing the battle? A systematic review. Int J Environ Res Public Health. 2015;12:1156-1173.

59. Subramanian SV, Perkins JM, Khan KT. Do burdens of underweight and overweight coexist among lower socioeconomic groups in India? Am J Clin Nutr. 2009;90:369-376.

60. Amorim PRS, de Faria RC, Byrne NM, Hills AP. Physical activity and nutritional status of Brazilian children of low socioeconomic status: Undernutrition and overweight. Asia Pac J Clin Nutr. 2006;15:217-223.

61. Tzioumis E, Adair LS. Childhood dual burden of under- and over-nutrition in low- and middle-income countries: A critical review. Food Nutr Bull. 2015;35:230-243.

62. Alhassan S, Sirard JR, Robinson TN. The effects of increasing outdoor play time on physical activity in Latino preschool children. Int J Pediatr Obes. 2007;2:153-158. 
Running Head: EFFECT OF PHYSICAL ACTIVITY ON EXECUTIVE FUNCTIONS

415

416

417

418

419

420

421

422

423

424

425

426

427

428

429

430

431

432

433

434

435

436

437

63. Alhassan S, Nwaokelemeh O, Mendoza A, Shitole S, Whitt-Glover MC, Yancey AK. Design and baseline characteristics of the Short bouTs of Exercise for Preschoolers (STEP) study. BMC Public Health. 2012;12:582-590.

64. Fitzgibbon ML, Stolley MR, Schiffer L, van Horn L, KauferChristoffel K, Dyer A. Hiphop to Health Jr. for Latino preschool children. Obesity. 2006;14:1616-1625.

65. Harvey-Berino J, Rourke J. Obesity prevention in preschool Native-American children: A pilot study using home visiting. Obes Res. 2003;11:606-611.

66. Bayer O, von Kries R, Strauss A, et al. Short- and mid-term effects of a setting based prevention program to reduce obesity risk factors in children: A cluster-randomized trial. Clin Nutr. 2009;28:122-128.

67. De Bock F, Genser B, Raat H, Fischer JE, Renz-Polster H. A participatory physical activity intervention in preschools: A cluster randomized controlled trial. Am J Prev Med. 2013;45:64-74.

68. Trost SG, Fees B, Dzewaltowski D. Feasibility and efficacy of a "Move and Learn" physical activity curriculum in preschool children. J Phys Activ Health. 2008;5:88-103.

69. Eliakim A, Nemet D, Balakirski Y, Epstein Y. The effects of nutritional-physical activity school-based intervention on fatness and fitness in preschool children. $J$ Pediatr Endocrinol Metab. 2007;6:711-718.

70. Hannon JC, Brown BB. Increasing preschoolers' physical activity intensities: An activity-friendly preschool playground intervention. Prev Med. 2008;46:532-536.

71. Reilly JJ, Kelly L, Montgomery C, Williamson A, et al. Physical activity to prevent obesity in young children: Cluster andomised controlled trial. BMJ. 2006;333:10411045. 
Running Head: EFFECT OF PHYSICAL ACTIVITY ON EXECUTIVE FUNCTIONS

438

439

440
72. Bellows LL, Davies PL, Anderson J, Kennedy C. Effectiveness of a physical activity intervention for Head Start preschoolers: A randomized intervention study. Am J Occup Ther. 2012;67:28-36.

73. Best JR. Exergaming immediately enhances children's executive function. Dev Psychol. 2011;48:1501-1510.

74. Chang Y-K, Liu S, Yu H-H, Lee Y-H. Effect of acute exercise on executive function in children with attention deficit hyperactivity disorder. Arch Clin Neuropsychol. 2012;27:225-237.

75. Piek JP, Barrett NC, Smith LM, Rigoli D, Gasson N. Do motor skills in infancy and early childhood predict anxious and depressive symptomology at school age? Hum Movement Sci. 2010;29:777-786.

76. Piek JP, Baynam GB, Barrett NC. The relationship between fine and gross motor ability, self-perceptions and self-worth in children and adolescents. Hum Movement Sci. 2006;25:65-75.

77. Skinner RA, Piek JP. Psychosocial implications of poor motor coordination in children and adolescents. Hum Movement Sci. 2001;20:73-94.

78. Piek JP, Dawson L, Smith LM, Gasson N. The role of early fine and gross motor development on later motor and cognitive ability. Hum Movement Sci. 2008;27:668-681.

79. Blair C, Granger DA, Willoughby M, et al. Salivary cortisol mediates effects of poverty and parenting on executive functions in early childhood. Child Dev. 2011;82: 1970-1984.

80. Blair C, Raver CC. Child development in the context of adversity: Experiential canalization of brain and behavior. Am Psychol. 2012;67:309-318. 